\section{El ejercicio de la acción por fraude de acreedores en contra de los fideicomisos bancarios}

\author{
Juan José Hopkins Broco
}

Abogado por la Universidad de Lima. Miembro y Ex-Director General de la Revista ADVOCATUS.

\section{Sandra Sofia Mercado Azurin}

Bachiller por la Pontificia Universidad Católica del Perú.

\section{SUMARIO:}

I. Introducción.

II. Fraude de acreedores y fideicomiso.

III. Remedio general: acción pauliana:

1. Naturaleza jurídica de la Acción Pauliana;

2. Titulares de la acción;

3. Requisitos para interponer una Acción Pauliana.

IV. Remedio especial: anulación del fideicomiso bancario prevista en la Ley de Bancos: 1. Naturaleza Jurídica;

2. Titulares de la acción;

3. Requisitos;

4. Consecuencias de la acción (nulidad del fideicomiso);

5. ¿Pueden interponerse ambas acciones en contra del fideicomiso bancario o debe preferirse una de ellas?

V. Propuesta de reforma de la ley de bancos con respecto a la acción por fraude de acreedores (artículo 245, Ley de Bancos).

VI. Remedio excepcional: ineficacia en la ley general del sistema concursal.

VII. Conclusiones. 


\section{INTRODUCCIÓN}

En los últimos años el uso del fideicomiso en el Perú se ha incrementado de manera exponencial. Mientras que en el año $2001^{\prime}$ el Perú contaba con 73 patrimonios fideicometidos constituidos y vigentes; a la fecha, las entidades fiduciarias administran ${ }^{2}$ alrededor de 420 patrimonios fideicometidos. Esto representa un crecimiento de más del $575 \%$ en el número de patrimonios fideicometidos administrados y, en consecuencia, un significativo crecimiento del mercado fiduciario peruano en estos últimos siete años.

Al analizar las cifras de crecimiento descritas en el párrafo precedente nos preguntamos ¿Cuáles son las razones por las que el fideicomiso se ha vuelto una figura tan atractiva para los distintos agentes? En nuestra opinión, la principal característica, y lo que hace interesante y atractiva a esta figura, es que mediante un contrato de fideicomiso se constituye un patrimonio autónomo que servirá para un único y exclusivo fin, el cual será establecido por las partes en el acto constitutivo o contrato de fideicomiso.

De esta forma, el fideicomiso proporciona un "blindaje" especial a quien lo constituye, ya que al transferir determinados bienes o derechos del patrimonio del fideicomitente a un patrimonio autónomo, todas las partes se aseguran que dichos bienes y derechos no responderán por las obligaciones del fideicomitente, del fiduciario o del fideicomisario. ${ }^{3}$ En consecuencia, el fideico- miso le asegura al fideicomisario que ninguna persona, autoridad o entidad gubernamental podrá ordenar que el patrimonio fideicometido sea utilizado para fines distintos a los establecidos en el contrato de fideicomiso.

El "blindaje", mencionado en el párrafo anterior, es proporcionado al patrimonio autónomo luego que se proceda a comunicar personalmente a los acreedores sobre la constitución del fideicomiso o se cumpla con publicar en el diario oficial un aviso informando respecto de la constitución de un patrimonio fideicometido. ${ }^{4}$

Es en este punto donde surge la importancia del tema a ser tratado en el presente artículo. Al obtener el patrimonio fideicometido el "blindaje" mencionado líneas arriba, y siempre que no existan vicios en su constitución, no existirá acción alguna que pueda traspasar el referido "blindaje" tanto por terceros ajenos a la figura como por los acreedores del fideicomitente. Contando, en este momento, el Fideicomisario con la seguridad de que el patrimonio fideicometido será utilizado por el fiduciario para los fines establecidos en el Contrato de Fideicomiso.

En conclusión, la acción por fraude de acreedores se constituye en la única acción legal con la que los acreedores del fideicomitente cuentan para atacar el patrimonio fideicometido a efecto de resguardar el cobro de sus respectivos créditos. De esta manera, el presente artículo busca aclarar las interrogantes más resaltantes

1 Fuente: Estadísticas Fiduciarias Comité Latinoamericano de Fideicomisos - COLAFI.

2 Fuente: La Fiduciaria S.A.

3 Artículo 253, Ley 26702: El patrimonio fideicometido no responde por las obligaciones del fiduciario o del fideicomitente ni de sus causahabientes y, tratándose de las obligaciones de los fideicomisarios, tal responsabilidad solo es exigible sobre los frutos o las prestaciones que se encuentran a disposición de ellos, de ser el caso.

En caso que la empresa fiduciaria no se oponga a las medidas que afecten al patrimonio fideicometido, pueden hacerlo el fideicomitente o cualquier fideicomisario. Uno y otros están facultados para coadyuvar en la defensa si la empresa fiduciaria hubiese hecho valer la oposición.

La empresa fiduciaria podrá delegar en el fideicomisario o en el fideicomitente las facultades necesarias para que ejerzan las medidas de protección del patrimonio fideicometido, sin quedar liberado de responsabilidad.

4 Artículo 245, Ley 26702: La acción para anular la transmisión fideicomisaria realizada en fraude de acreedores caduca a los seis (6) meses de publicado en el Diario Oficial, por tres (3) días consecutivos, un aviso que dé cuenta de la enajenación. En todo caso, esa caducidad opera a los dos (2) meses de la fecha en que el acreedor haya sido notificado personalmente de la constitución del fideicomiso. 
que podrian tener los acreedores para cuestionar la correcta constitución del patrimonio fideicometido.

\section{FRAUDE DE ACREEDORES Y FIDEICOMISO}

Nos parece importante iniciar el desarrollo este artículo delimitando brevemente el concepto jurídico de fraude de acreedores. Un acto jurídico será considerado fraudulento cuando este tenga como único fin la enajenación de bienes -a título oneroso o gratuito-, que realiza un deudor a efecto que su o sus acreedores no puedan hacer cobro de sus créditos mediante la ejecución de dichos bienes. ${ }^{5}$ Asimismo, también constituye fraude de acreedores la renuncia del deudor a ciertos derechos que podrían haber ingresado a su patrimonio, la constitución de garantías en respaldo de deudas ajenas -cuando se tienen deudas propias-o de un àcreedor en detrimento de los demás.

No debemos confundir el fraude que se menciona en estas páginas con el fraude a la ley. La principal diferencia entre dichas figuras es que, en el primero, quien comete el fraude busca producir el acto jurídico a efecto de sacar de su patrimonio los bienes y derechos que podrían ser ejecutados por el acreedor. En el segundo, las partes buscan evitar los efectos de alguna ley mediante la celebración de un acto jurídico; en consecuencia, lo buscado por las partes no es el acto jurídico sino eludir de manera fraudulenta los efectos de una determinada ley.

Volviendo a nuestro tema, antes de entrar a analizar si el fideicomiso puede ser utilizado erróneamente como una herramienta para defraudar acreedores, resulta necesario citar la definición que recoge nuestra normativa sobre el fideicomiso. De acuerdo al artículo 241 de la Ley 26702, Ley General del Sistema Financiero y del Sistema de Seguros y Orgánica de la Superintendencia de Banca y Seguros (en adelante, Ley de Bancos), el fideicomiso es "una relación jurídica por la cual el fideicomitente transfiere bienes en fideicomiso a otra persona, denominada fiduciario, para la constitución de un patrimonio fideicometido, sujeto al dominio fiduciario de éste último y afecto al cumplimiento de un fin especifico en favor del fideicomitente o un tercero denominado fideicomisario".

Más allá de los defectos de los que adolece la citada definición, defectos que serán desarrollados en un artículo posterior, es importante destacar que bajo el ordenamiento legal peruano mediante la celebración de un contrato de fideicomiso, una persona natural o jurídica, denominada fideicomitente, transfiere determinados bienes a un patrimonio autónomo para que otra entidad, denominada fiduciario, los administre; el fiduciario ejercerá el dominio fiduciario sobre dicho patrimonio autónomo. La administración de dicho patrimonio autónomo o patrimonio fideicometido será realizada por el fiduciario en beneficio del mismo fideicomitente o de una tercera persona natural o jurídica, denóminada fideicomisario.

Pero, ¿qué es el dómino fiduciario? De acuerdo al artículo 4 de la Resolución de la Superintendencia de Banca y Seguros No. 1010-99, Reglamento del Fideicomiso y de las Empresas de Servicios Fiduciarios (en adelante, el Reglamento), el dominio fiduciario es "el derecho de carácter temporal que otorga al fiduciario las facultades necesarias sobre el patrimonio fideicometido, para el cumplimiento del fin o fines del fideicomiso, con las limitaciones establecidas en el acto constitutivo (...).". Por su lado, el artículo 252 de la Ley de Bancos establece que el dominio fiduciario le confiere al fiduciario "plenas potestades, incluidas las de administración, uso, disposición y reivindicación, sobre los bienes que conforman el patrimonio fideicometido (...)".

De acuerdo a lo expuesto podemos establecer como punto de partida que el ordenamiento jurídico peruano dispone que el dominio fiduciario confiere al fiduciario plenas potestades

5 VIDAL RAMIREZ, Fernando, El Acto Jurídico, Sexta Edición, Gaceta Jurídica, Lima, 2005, p. 452. 
para realizar los actos que sean necesarios para cumplir con los fines establecidos para el patrimonio fideicometido en el contrato de fideicomiso; con lo cual, el fiduciario posee las facultades de reivindicación, uso, disposición y administración de los bienes transferidos al patrimonio fideicometido. Las primeras tres facultades son similares a las que ejercería cualquier propietario de un bien; sin embargo, el fiduciario ve limitadas las mencionadas facultades tanto temporalmente como por lo dispuesto en el contrato de fideicomiso.

Teniendo clara la estructura básica de un fideicomiso, pasaremos a explicar cómo ésta figura puede ser erróneamente utilizada en el fraude de acreedores.

Imaginemos que un deudor transfiere determinados bienes a un patrimonio fideicometido en respaldo de la deuda que mantiene con una empresa vinculada. Obviamente la empresa vinculada jamás buscará ejecutar la garantía fiduciaria ni buscará hacerse cobro de la deuda garantizada, con lo cual el fideicomiso se habrá constituido con el único fin de aislar los bienes del deudor a efecto que no puedan ser embargados o vendidos por sus demás acreedores. En consecuencia, se habría constituido un fideicomiso para defraudar a los acreedores de nuestro deudor; siendo la única intención del fideicomitente beneficiarse de la protección y blindaje que le otorga el fideicomiso.

En consecuencia, es importante -tanto para los acreedores como para los deudores- conocer cuáles son las acciones que pueden iniciarse en caso se constituya un fideicomiso fraudulento. El ordenamiento jurídico peruano establece tres posibles acciones o remedios en contra de un fideicomiso constituido en fraude de acreedores; estas son: (i) la acción pauliana, prevista por el Código Civil; (ii) la acción de nulidad de fideicomiso, prevista por la Ley de Bancos; y (iii) la acción de ineficacia concursal, prevista por la Ley General del Sistema Concursal.
A continuación procederemos a detallar brevemente cada una de las acciones mencionadas y emitiremos nuestra opinión acerca de cuáles podrán ser utilizadas en contra del fideicomiso constituido en fraude de acreedores. Empezaremos por la acción general, la acción pauliana.

\section{REMEDIO GENERAL: ACCIÓN PAULIANA}

\section{Naturaleza Jurídica de la Acción Pauliana}

Durante mucho tiempo se ha discutido si la acción pauliana es una acción real o una personal. Hoy en día, la doctrina es casi unánime en afirmar que la acción pauliana es una acción personal o creditoria. Así lo afirma Fernando Vidal cuando señala que "la acción pauliana es creditoria, ya que de ser real el acreedor tendría que tener un derecho especifico sobre un bien, que seria el que los legitima para accionar. El acreedor acciona en virtud de una relación obligacional que ha dado lugar a la constitución del crédito, por lo que la acción que se deriva es de carácter creditorio".6

En tal sentido queda claro que, en un sentido general, la acción pauliana es una acción personal, ya que la misma deriva de la relación contractual y obligacional existente entre acreedor y deudor.

De otro lado, en un sentido más específico, queda claro - de la redacción del artículo 195 del Código Civil- que la acción pauliana genera únicamente la ineficacia del acto jurídico fraudulento frente al acreedor que haya interpuesto la mencionada acción.

\section{Titulares de la acción}

La acción pauliana puede ser interpuesta por cualquier acreedor que sienta que un acto jurídico celebrado por su deudor ha sido realizado con la finalidad de evadir el pago de su respectiva acreencia. En ese orden de ideas, la acción pauliana puede ser interpuesta por cualquier acreedor que mantenga deudas no solventadas 
frente a un deudor y que, por lo tanto, tienen un legítimo interés en conservar el patrimonio del referido deudor.

Cabe mencionar que incluso si su crédito está sujeto a condición o a plazo suspensivo, el acreedor podrá interponer la acción pauliana en contra de cualquier acto jurídico fraudulento del deudor cumpliendo con los requisitos establecidos en artículo 195 del Código Civil, los mismos que procederemos a detallar a continuación.

\section{Requisitos para interponer una Acción Pauliana}

A efecto de ejercer una acción pauliana es necesario que se presenten dos requisitos básicos: (i) el perjuicio del acreedor y (ii) el carácter fraudulento del acto jurídico celebrado por el deudor.

El perjuicio del acreedor es un requisito objetivo. Dicho requisito se verifica cuando un acto jurídico causa que el patrimonio del deudor no sea suficiente para atender o respaldar genéricamente sus deudas. Ponemos un ejemplo para entender mejor este tema.

Imaginemos que Juan Pérez tiene activos por un valor total de 500 y tiene deudas que ascienden a 350 . Bajo este supuesto sus acreedores se sentirían seguros ya que los activos de Juan son suficientes para cubrir el íntegro de sus deudas. Imaginemos ahora que Juan se desprende de activos por un valor de 200, manteniendo activos por 300 . Bajo este nuevo supuesto, en caso Juan tenga que pagar todas sus obligaciones habrá un saldo de 50 que no podrá ser saldado por Juan, ya que no tiene activos suficientes para hacer frente al total de sus deudas. Es este último supuesto lo que se conoce como el perjuicio del acreedor.

De otro lado, el carácter fraudulento del acto jurídico es el requisito subjetivo de la acción pauliana. Este se verifica cuando el deudor celebra un acto jurídico con la intención de dañar o causar perjuicio a su acreedor o acreedores. En tal sentido, para que se verifique el carácter fraudulento del acto jurídico es necesario que el tercero adquirente de los bienes conozca el perjuicio o daño que se le estaría causando al acreedor o acreedores.

Como claramente establece el artículo 195 del Código Civil, siempre será necesario en la presentación de una acción pauliana probar el requisito objetivo o perjuicio del acreedor, mientras que solo será necesario probar el requisito subjetivo o carácter fraudulento del acto cuando nos encontremos ante actos jurídicos fraudulentos onerosos, celebrados simultáneamente o posteriormente al otorgamiento del crédito por parte del acreedor; mientras que para actos onerosos celebrados previamente al otorgamiento del crédito será necesario probar que el deudor y el tercero celebraron el acto con el propósito de perjudicar al deudor, es decir, no será suficiente probar solo conocimiento, será necesario probar intención de daño. En resumen, para los actos juridicos gratuitos no será necesario probar el carácter fraudulento del acto jurídico.

Para culminar con esta breve explicación sobre la acción pauliana, cabe mencionar que dicha acción prescribe, de acuerdo a lo establecido en el artículo 2001 del Código Civil, en un plazo de dos años contados desde la celebración del acto jurídico fraudulento.

\section{REMEDIO ESPECIAL: ANULACIÓN DEL FIDEICOMISO BANCARIO PREVISTA EN LA LEY DE BANCOS}

\section{Naturaleza Jurídica}

Con respecto a la acción de anulación del fideicomiso bancario prevista en el artículo 245 de la Ley de Bancos, la cual llamaremos en adelante "acción de anulación", pensamos que la misma -al igual que la acción pauliana- también es de carácter personal.

Creemos esto porque, al igual que la acción pauliana, la acción de anulación puede ser presentada por cualquier persona que tenga un crédito vigente con su deudor y que se sienta perjudicado con el acto de disposición que dicho deudor ha realizado. En tal sentido,

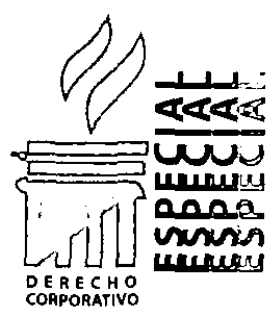


siendo que el crédito se desprende de una relación obligacional y no una real, la acción de anulación debe ser considerada como una acción personal.

Asimismo, como su mismo nombre lo dice, la acción de anulación busca anular un fideicomiso bancario constituido fraudulentamente, atacando la validez del acto antes que la eficacia. Esta es -a nuestro entender- la principal diferencia entre la acción pauliana y la acción de anulación, ya que la pauliana causa la ineficacia del acto mientras que la de anulación causa la nulidad del fideicomiso bancario.

\section{Titulares de la acción}

La Ley de Bancos, a diferencia del Código Civil, no establece qué acreedores pueden presentar la acción de anulación. Sin embargo creemos que no habría problemas en considerar que los mismos acreedores que podrían presentar una acción pauliana a su vez se encuentran legitimados para presentar una acción de anulación.

Creemos que, ante la falta de regulación de este tema en la Ley de Bancos, es perfectamente posible aplicar por analogía las reglas establecidas en el Código Civil, ya que estamos hablando de dos acciones que sirven como remedio para el fraude de acreedores. En consecuencia, si un acreedor tiene derecho a presentar una acción pauliana debería tener derecho para presentar una acción de anulación.

\section{Requisitos}

La Ley de Bancos no es tan clara en este tema como el Código Civil; sin embargo, la norma nos menciona la "acción para anular la transmisión fideicomisaria realizada en fraude de acreedores $(\ldots)^{\prime \prime}$. En tal sentido, de acuerdo a lo regulado, entendemos que los requisitos necesarios para la presentación de una acción de anulación deberían ser los mismos que los descritos para una acción pauliana. En ese orden de ideas, los requisitos básicos para la acción de anulación serán el perjuicio del acreedor o acreedores y la celebración del fideicomiso con el ánimo de defraudar al acreedor o acreedores, es decir que tanto el fideicomitente como el fiduciario $-y$ el fideicomisario en tanto partícipe en el acto constitutivo- hayan tenido conocimiento que la constitución del fideicomiso tenía como fin ulterior perjudicar o dañar al acreedor o acreedores del fideicomitente.

Respecto a este último punto, entendemos que por la gravedad de la consecuencia jurídica que el artículo 245 de la Ley de Bancos impone a la acción de anulación -nulidad del fideicomiso-y ante el silencio regulatorio de la Ley de Bancos, es necesario que para cualquier fideicomiso -ya sea gratuito $u$ oneroso- se pruebe el requisito subjetivo antes planteado. De no ser demostrado dicho requisito por el acreedor, la acción de anulación debería ser rechazada.

De otro lado, cabe preguntarse, ¿será posible que se presente una acción de anulación en contra de un fideicomiso que se constituyó previamente al otorgamiento del crédito pero con la única intención de perjudicar al acreedor? En nuestra opinión, y nuevamente basándonos en las reglas para la acción pauliana, no debería haber inconvenientes en que el acreedor anule un fideicomiso con las características antes nombradas, pero siempre probando los requisitos arriba mencionados.

Sin perjuicio de dichos requisitos generales, debe tenerse en cuenta el plazo con el que los acreedores cuentan para interponer la acción de anulación.

De acuerdo a lo regulado en el artículo 245 de la Ley de Bancos, el plazo de caducidad para que los acreedores puedan interponer la acción de anulación en contra de un fideicomiso fraudulento corre desde que le es comunicada al respectivo acreedor la celebración del referido fideicomiso.

Según la Ley de Bancos, hay dos formas de comunicar la celebración de un contrato de fideicomiso a los acreedores del fideicomitente: (i) a través de la publicación en el Diario Oficial El Peruano por tres días consecutivos; y (ii) directa y personalmente. En el primer supuesto, el plazo de caducidad es de seis meses contados desde 
la última publicación en El Peruano y, en el segundo supuesto, es de dos meses desde que el acreedor recibe la comunicación. A estos plazos se les conoce normalmente como período de sospecha del fideicomiso.

Como se puede observar el plazo para la presentación de la acción de anulación, comparado con el plazo de la acción pauliana, es considerablemente más corto. En nuestra opinión esto se debe a dos razones: (i) que existe la obligación legal de comunicar a los acreedores del fideicomitente sobre la celebración del contrato de fideicomiso, lo cual hace que los acreedores puedan conocer fácilmente sobre la constitución de un fideicomiso con respecto a su deudor; y (ii) la consecuencia legal regulada para la acción de anulación que es mucho más grave que la prevista para la acción pauliana.

Otra diferencia con la acción pauliana que salta a la vista, es que el plazo para interponer la acción es de caducidad y no de prescripción, con las consecuencias que ello ocasiona (suspensión del plazo, plazo fatal, etc.).

\section{Consecuencias de la acción (nulidad del fideicomiso)}

Como su mismo nombre lo dice y mencionamos anteriormente, la consecuencia en caso se declare fundada la acción de anulación presentada por cualquier acreedor será la nulidad del fideicomiso en cuestión.

Dicha nulidad, de acuerdo a lo regulado por el artículo 222 del Código Civil, se retrotraerá a la fecha de celebración del fideicomiso y, por lo tanto, el fiduciario procederá a restituir a favor del fideicomitente los bienes transferidos en dominio fiduciario, y como consecuencia de ello, se entenderá como que el fideicomiso jamás hubiese existido. En consecuencia, por la mencionada declaración de nulidad, se beneficiará no solo al acreedor que fue diligente y presentó la acción, sino a todos los acreedores del deudor.

Con respecto a las consecuencias de la acción de anulación, encontramos varias diferencias con respecto a la acción pauliana. La primera, y más importante, es la consecuencia de la acción en sí misma, mientras en la acción pauliana hablamos de una ineficacia del acto, en la acción de anulación estaremos ante la nulidad del fideicomiso. Asimismo, con respecto a quienes beneficia o afecta cada una de las acciones, mientras que en la acción pauliana el único beneficiado será el acreedor que interpuso la acción; en la acción de anulación se verán beneficiados con la restitución al patrimonio del deudor de los bienes fideicometidos todos los acreedores, ya que el fideicomiso será declarado nulo.

\section{5. ¿Pueden interponerse ambas acciones en contra del fideicomiso bancario $o$ debe preferirse una de ellas?}

En nuestra opinión no podría interponerse ambas acciones. Es más, creemos que en caso se suscriba un fideicomiso bancario en fraude de acreedores, los acreedores solo podrían interponer la acción de anulación, no siendo posible presentar una acción pauliana en contra de un fideicomiso bancario.

Nuestra opinión se basa en el principio general de derecho: "ley especial prima sobre ley general". En este caso, la Ley de Bancos-ley especial- ha regulado un proceso específico para los fideicomisos bancarios constituidos en fraude de acreedores, constituyendo la acción pauliana el mecanismo general regulado por el Código Civil-ley general-. En consecuencia, siendo que existe una norma especial que regula el supuesto de hecho "fideicomiso bancario constituido en fraude de acreedores", no será de aplicación lo establecido en la norma general para el supuesto acto jurídico celebrado en fraude de acreedores.

Asimismo, no debemos olvidar que -de acuerdo al artículo IX del Título Preliminar del Código Civil- las normas de dicho cuerpo legal son supletorias y se aplican en caso de vacíos de otras leyes. En este caso no existe vacio con respecto a los fideicomisos bancarios celebrados en fraude de acreedores, por lo que no será posible aplicar las normas del Código Civil para dicho supuesto de hecho.

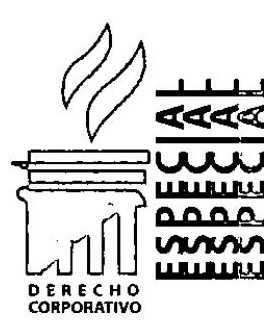


No debemos confundir la consecuencia jurídica que impone la norma con el supuesto de hecho que esta regula, es cierto que las consecuencias que acarrea la acción pauliana y las consecuencias que acarrea la acción de anulación son distintas. Pero ambas están pensadas para regular el mismo supuesto de hecho, es decir, el fraude de acreedores respecto a las transferencias que realice su deudor. En conclusión, al regular ambas normas el mismo supuesto de hecho, debemos siempre preferir la norma especial sobre la general.

\section{PROPUESTA DE REFORMA DE LA LEY DE BANCOS CON RESPECTO A LA ACCIÓN POR FRAUDE DE ACREEDORES (ARTÍCU- LO 245, LEY DE BANCOS)}

Hasta este punto hemos llegado a la conclusión de que la única acción que procede en contra de un fideicomiso celebrado en fraude de acreedores es la acción de anulación. Sin embargo, pensamos que la acción de anulación no se encuentra regulada eficientemente por la Ley de Bancos y, por lo tanto, debería ser modificada en base a los argumentos que a continuación procedemos a describir.

En primer lugar, pensamos que la consecuencia de la acción de anulación debería ser, al igual que para el caso de la acción pauliana, la ineficacia del fideicomiso únicamente frente al acreedor que presentó la demanda. Creemos que la nulidad de un fideicomiso como solución del fraude de acreedores puede traer consecuencias perjudiciales frente a otro grupo de personas, nos explicamos.

Pensemos por un momento en un fideicomiso de administración de derechos de cobro y flujos dinerarios en el que se le encarga a un fiduciario servir como tesorero del fideicomitente, es decir, realizar todos los pagos -incluyendo sueldos, proveedores, etc.- que el fideicomitente le ordene o solicite.

Para el caso planteado, asumamos que un acreedor del fideicomitente se siente defraudado por la constitución de dicho fideicomiso porque dichos derechos de cobro y flujos dinerarios transferidos son los únicos bienes con los que cuenta el fideicomitente para atender sus deudas $y$, por lo tanto, el pago que el fideicomitente debe realizar al acreedor quedará sujeto al designio de aquel, ya que el fideicomitente es el único que puede ordenar al fiduciario realizar el pago y al destino de los fondos, de acuerdo a la prelación establecida en el acto constitutivo. Recordemos en este punto que un fiduciario actúa de acuerdo a lo descrito en el contrato de fideicomiso, en la Ley de Bancos o por las instrucciones del fideicomitente o fideicomisario, de ser el caso.

En tal sentido, siendo que -desde la suscripción del fideicomiso en adelante- nuestro acreedor no tendrá ningún bien con el cual hacerse cobro de su crédito, decide interponer una acción de anulación en contra del mencionado fideicomiso.

Luego de un arduo proceso que dura alrededor de cinco años llegando hasta la Corte Suprema, nuestro acreedor logra el éxito y se declara nulo el fideicomiso. Como es sabido y mencionamos líneas arriba, la nulidad retrotrae sus efectos a la celebración del acto, por lo que cualquier acto realizado por el fiduciario desde ese momento en adelante sería nulo también.

En consecuencia, serían declarados nulos todos los pagos realizados por el fiduciario en el marco del contrato de fideicomiso y el fiduciario o los terceros que recibieron el pago -este punto no nos queda claro y ni la Ley de Bancos ni el Código Civil aclaran el tema- deberán devolver el dinero que fue pagado, en virtud a lo establecido en nuestro contrato de fideicomiso, hoy declarado nulo.

Resulta imposible llevar a la realidad lo descrito líneas arriba. No se pueden declarar nulos todos los actos de disposición realizados por el fiduciario en el marco de la administración del fideicomiso. En todo caso, la logística para recabar todos los pagos tomaría más tiempo que el proceso mismo y, probablemente, sería más costosa.

De otro lado, otra razón por la que pensamos que la nulidad no es la solución correcta para 
el fraude de acreedores ya que -como lo señaláramos antes-con la nulidad del fideicomiso se verían beneficiados todos los acreedores del fideicomitente, no solo el que presentó la demanda. Con lo cual, aquellos acreedores que no fueron diligentes y dejaron vencer el plazo o que, sencillamente, no tenían interés o no se sentían perjudicados por la constitución del fideicomiso, se verán sorpresivamente beneficiados con la nulidad del fideicomiso y posterior restitución de los bienes al patrimonio del fideicomitente y deudor. Por lo tanto, se estaría otorgando un beneficio a aquellos que fueron negligentes y dejaron vencer el período de sospecha y se estaría perjudicando a los fideicomisarios quienes verían anulado el fideicomiso que los beneficiaba.

En conclusión, por las razones antes expuestas, pensamos que la mejor solución o remedio para el fraude de acreedores es la declaración de ineficacia frente al acreedor accionante del fideicomiso fraudulento. De esta manera, se otorga protección al acreedor que considera que el fideicomiso lo está perjudicando, se protege el negocio celebrado por el fideicomitente y el fiduciario, se protege el beneficio que recibía el o los fideicomisarios y se evitaría el problema de retrotraer los efectos de la nulidad a la suscripción del fideicomiso. De esta manera, el acreedor podrá iniciar las medidas necesarias para que, en caso el fideicomitente no cumpla con sus deudas, pueda solicitar el embargo de los derechos de cobro y flujos dinerarios transferidos al patrimonio fideicometido que ha sido declarado ineficaz.

En consecuencia, en nuestra opinión, el artículo 245 de la Ley de Bancos debe ser reformado a efecto de establecer la ineficacia del fideicomiso en vez de la nulidad del mismo.

\section{REMEDIO EXCEPCIONAL: INEFICACIA EN LA LEY GENERAL DEL SISTEMA CONCURSAL}

Antes de culminar con el presente artículo, nos parece importante hablar brevemente sobre el último remedio que da la ley para los actos jurídicos fraudulentos. Este es la declaración de ineficacia de los actos de disposición regulada en la Ley 27809, Ley General del Sistema Concursal (en adelante "Ley Concursal").

De acuerdo al artículo 19 de la Ley Concursal el juez declarará ineficaces y, en consecuencia, inoponibles frente a los acreedores del concurso, los gravámenes, transferencias, contratos y demás actos jurídicos, sean a título gratuito u oneroso, que no se refieran al desarrollo normal de la actividad del deudor, que perjudiquen su patrimonio, cuando estos hayan sido celebrados: (i) un año antes desde que el deudor presentó su solicitud para acogerse a algún procedimiento concursal o desde que fue notificado de la resolución de emplazamiento o fue notificado con la resolución de disolución y liquidación; o (ii) en el período comprendido entre el momento en que el deudor presentó su solicitud para acogerse a algún procedimiento concursal o desde que fue notificado de la resolución de emplazamiento o fue notificado con la resolución de disolución y liquidación hasta el momento en que la Junta de Acreedores nombre o ratifique a la administración del deudor.

Hay muchas aristas con respecto al proceso de ineficacia concursal detallado en el artículo 19 de la Ley Concursal, los cuales no son materia del presente trabajo. Lo que nos parece importante resaltar es que dicho proceso acarrea la ineficacia e inoponibilidad frente a los acreedores concursales de los actos jurídicos celebrados por el deudor antes y durante el inicio del concurso, la reincorporación de los bienes materia de dichos actos jurídicos a la masa concursal, es iniciado a solicitud de la Junta de Acreedores y es tramitado judicialmente en la vía sumarísima.

Con respecto a este proceso y los fideicomisos bancarios, nos preguntamos, en caso un deudor sometido a concurso celebre un fideicomiso bancario dos meses antes de su sometimiento a procedimiento concursal $¿$ los acreedores deberán iniciar un proceso de nulidad de fideicomiso según la Ley de Bancos o deberán iniciar un proceso de ineficacia de fideicomiso según la Ley Concursal?

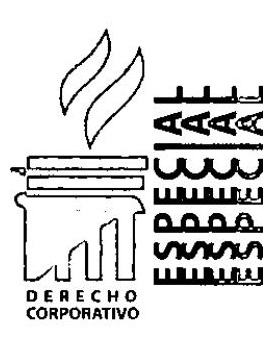


La respuesta a dicha interrogante no es senciIla, con respecto a la acción pauliana era claro que el código civil era la ley general y la Ley de Bancos la norma especial. Sin embargo, si comparamos la Ley Concursal y la Ley de Bancos nos encontraremos frente a dos normas especiales, una respecto a la constitución de fideicomisos y la otra con respecto al procedimiento concursal. En consecuencia, será muy difícil aplicar el principio general de derecho de norma especial.

Sin perjuicio de ello, en nuestra opinión el remedio aplicable debería ser en todo supuesto la acción de anulación ya que es el remedio especial regulado por la Ley de Bancos para un fideicomiso. En consecuencia, si estamos dentro de un procedimiento concursal podremos considerar como la norma general para dicho procedimiento a la Ley Concursal y como la norma especial a la Ley de Bancos.

Recordemos que el fideicomiso es una figura que se encuentra únicamente regulada en la Ley de Bancos y en su respectivo reglamento, es por ello, que argumentamos que las reglas que deben aplicarse para cualquier controversia respecto a la citada figura contractual deberán ser las contenidas en la Ley de Bancos, supletoriamente deberán aplicarse otros cuerpos legales como el Código Civil o la Ley Concursal.

Sin embargo, somos conscientes que el argumento puede ser rebatido y considerarse a la Ley Concursal como la norma especial. En conclusión, es un tema que no tiene una solución pacífica.

\section{CONCLUSIONES}

El fideicomiso es un acto jurídico que otorga un blindaje potente constituyéndose un patrimonio autónomo y separado del patrimonio del fideicomitente. En consecuencia, podría ser utilizado para aislar los bienes de las personas a efecto que sus acreedores no puedan embargar y/o ejecutar los mismos.

Siendo que hay una norma especial para los fideicomisos bancarios fraudulentos, no será aplicable para dichos actos jurídicos la acción pauliana regulada por el Código Civil. Solo será posible que los acreedores inicien la acción de anulabilidad prevista por el artículo 245 de la Ley de Bancos.

Es necesario modificar el artículo 245 de la Ley de Bancos a efecto de modificar la consecuencia juridica para los fideicomisos bancarios fraudulentos. Lo más conveniente, según los argumentos planteados, sería que se previera la ineficacia para dicho supuesto y no la nulidad como se encuentra hoy en dia regulada.

Cabe mencionar que dicho cambio ya fue introducido por nuestros legisladores en el Código Civil de 1984, ya que la acción pauliana según estaba regulada en el Código Civil de 1936 era un proceso que acarreaba la nulidad del acto jurídico fraudulento.

Con respecto al conflicto entre la acción de anulación prevista en la Ley de Bancos y la acción de ineficacia concursal prevista en la Ley Concursal, no hay una respuesta clara al respecto. Sin embargo, en nuestra opinión debería preferirse la acción de anulación prevista en la Ley de Bancos, al ser el mecanismo especial regulado para los fideicomisos bancarios. 